\title{
Design of Non-contact Height Detecting System for a Marine Diesel Engine
}

\author{
Xinglong Pan $^{1, a}$, Guo $\mathrm{He}^{2, \mathrm{~b}}$ \\ ${ }^{1}$ College of Power Engineering, Naval University of Engineering, Wuhan, 430033, China \\ ${ }^{2}$ Department of Management Engineering, Naval University of Engineering, Wuhan, 430033, China \\ aemail: paxilo619@163.com, bemail:heguo953760@163.com
}

Keywords: Marine Diesel Engine; Air Spring; Single Chip Microcomputer; Ultrasonic; Non-contact Detection; System Design

\begin{abstract}
Air pressure is an important parameter for the air spring on a marine diesel engine. The pressure can be indirect reflected according to the spring camber, and the spring camber means the distance variation among the measuring points of air spring. So, in order to obtain the air pressure of marine diesel engine air spring, automatic non-contact height detecting system is designed based on single chip microcomputer and ultrasonic transducer. By using the proposed automatic detection system, the height of each measuring points of air spring can be obtained timely and accurately, and the air pressure keep in normal range is realizable.
\end{abstract}

\section{Introduction}

Diesel engine is widely used in vehicle and watercraft, as a reciprocating machinery, compared of other rotary machinery, such as steam turbine and gas turbine, the weakness of diesel engine is the highly vibration and noise. So, a special vibration and noise reduction equipment is necessary for a diesel engine, especially for a marine diesel engine on a modern ship. Air spring is a kind of effective vibration isolation equipment which is used in a certain marine diesel engine[1,2]. The schematic diagram of air spring in a ship is shown in Fig.1.

Diesel engine

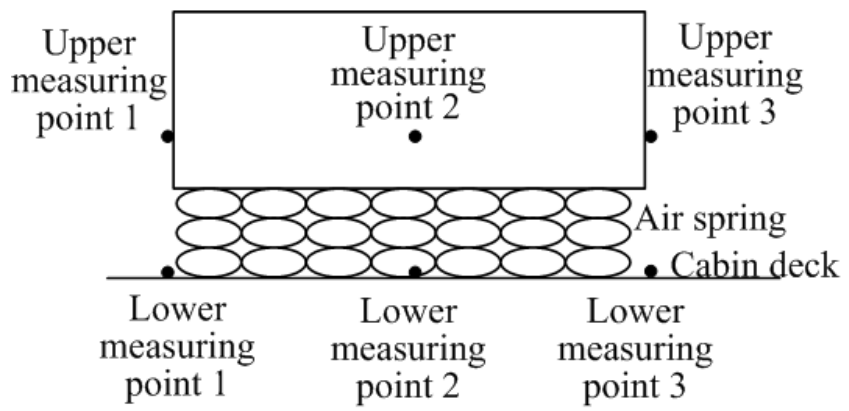

Fig.1. Schematic diagram of diesel and air spring

As shown in Fig.1, air spring is layout between diesel engine and cabin deck, which is consist of many air bags called airbag array.

Air pressure is an important parameter for the air spring. To ensure the work effect of the air spring, the air pressure must be kept in normal range for all of the air bags. When the air pressure of one or some air bag down to lower limit value of normal range, it should be replenished. And when the air pressure elevated to upper limit value of normal range, the air supplement should be stopped.

\section{Air Pressure Measurement Method}

Generally, the measurement method contains direct measurement and indirect measurement. For the air pressure of the marine diesel engine air spring, direct measurement means we should detect the air pressure of every air bag directly, while indirect measurement means it is unnecessary to detect the air pressure parameter value for every air bag. In fact, the field parameter value of the 
marine diesel engine air spring is obtained according to the spring camber indirectly. The measuring principle is that the relationship between air pressure and spring camber is liner dependence. A higher pressure value means a smaller spring camber, which is equal to a bigger height value between the upper measuring point and lower measuring point in Fig.1. In the same way, if the pressure value of the air bag is lower, and then the spring camber is more obviously, which means the height value between the upper measuring point and lower measuring point is smaller in Fig. 1. So we can get the air pressure value of air spring by measuring the height value of the given measuring points as shown in Fig. 1 indirectly. The field measuring points are shown in Fig. 2.

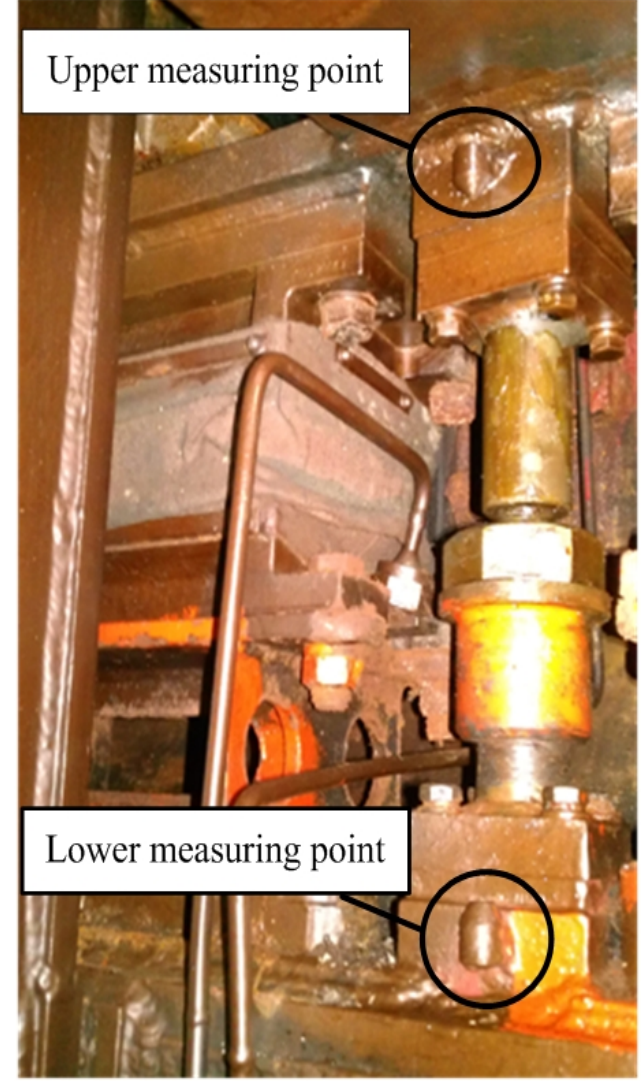

Fig.2. Field measuring point

Unfortunately, as showing in Fig. 1 and Fig. 2, the field measuring points are arranged in narrow space. The upper measuring point is fixed on the diesel engine, and the lower measuring point layout the cabin deck. The result is that it is very difficult for the field measurement depends on manual detection only, and the measurement result can't be obtained timely and accurately. So, we need automatic height detection and control system to ensure the air pressure keep in the normal range.

\section{Automatic Height Detecting System Design}

The proposed automatic height detecting system of marine diesel engine air spring is a non-contact measurement system based on ultrasonic principle, by using single chip microcomputer as a controller[3,4]. The general scheme of the system is shown in Fig. 3.

As shown in Fig. 3 the given detecting system is composed of 4 parts, which is height detection module, air supply module, output display module, and temperature compensation module. The specific description for each part of the system is shown as follow. 


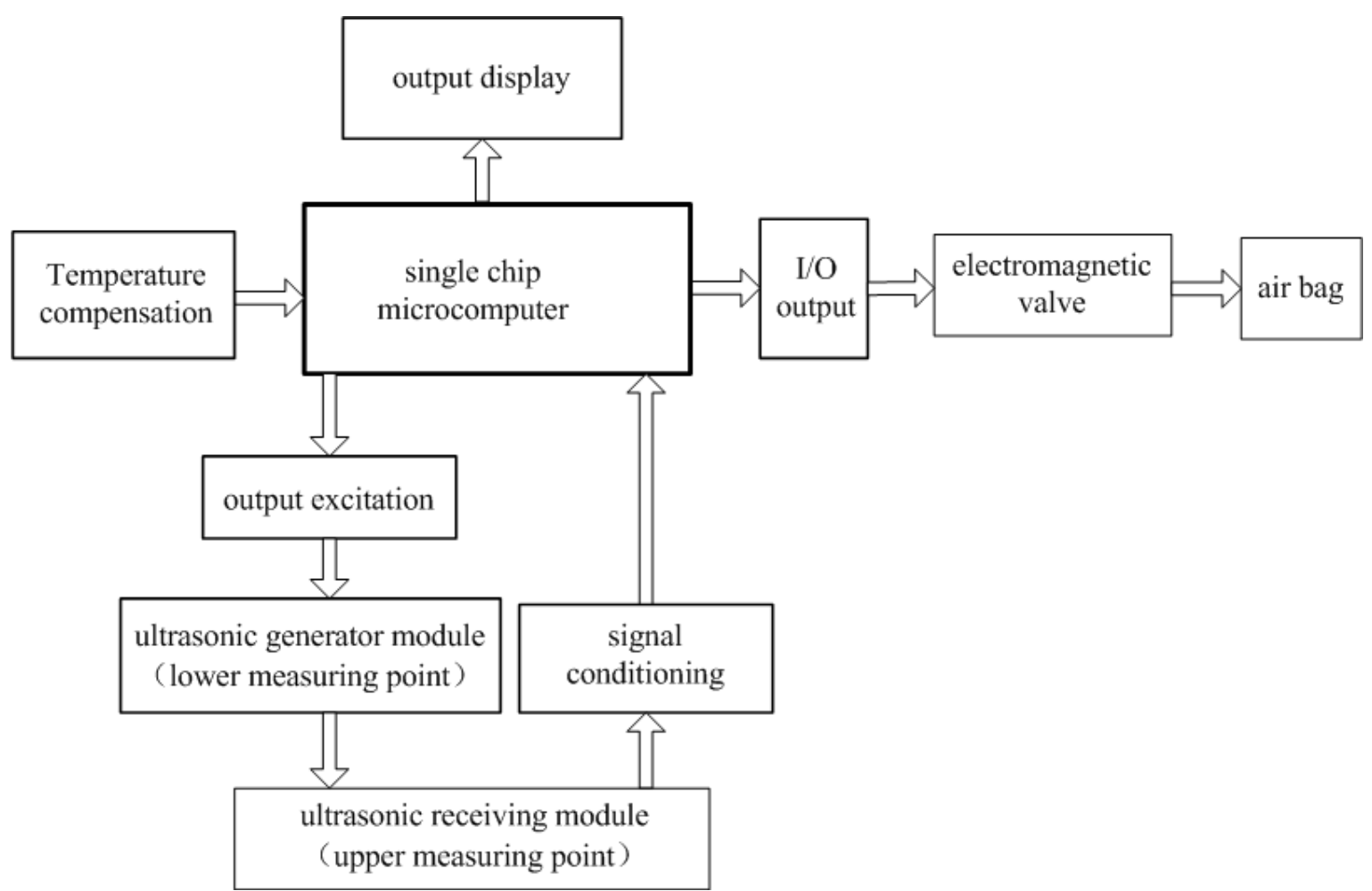

Fig.3. General scheme of automatic height detecting system

\section{Function Module Analysis}

\section{(1) Height detection module}

The key point of the height detection module is single chip microcomputer. By means of the single chip microcomputer, the height value between upper measuring point and lower measuring point can be obtained according to equation (1).

$$
s=C \Delta t
$$

Where, $C$ is acoustic velocity, $\Delta t$ is the duration time of ultrasonic signal transmit from lower measuring point to upper measuring point, which is the time difference of timer T1 and timer T2 in the single chip microcomputer. In order to get the parameters in equation (1), following functional unit should be contained, such as output excitation, ultrasonic generation, ultrasonic reception, and signal processing, and so on.

a) Single chip microcomputer

The type of STM32 single chip microcomputer is chosen as controller of the automatic height detecting system because of the excellent performance of STM32, including the $72 \mathrm{MHz}$ maximum frequency, 12-bit A/D converters (contains 21 channels and the conversion time is only 1 $1 \mu \mathrm{s}$ ), 12-bit D/A converters, 12-channel DMA controller, 80 fast I/O port, 7 timers, and 9 communication interfaces, which can meet the requirement of the system[5-7].

b) Output excitation

According to the characteristics of ultrasonic, pulsing signal is required to for ultrasonic range finder. In our project, $40 \mathrm{KHz}$ pulse signal is produced as output excitation by using single chip microcomputer.

c) Ultrasonic generation

The ultrasonic generation mechanism is depends on inverse piezoelectric effect, which means when electrical signal, such as a pulsing signal, imposed on piezoelectric ceramics, it will be converted into ultrasonic signal. Therefore, piezoelectric ceramics play a key role for ultrasonic generation.

d) Ultrasonic reception

The structure of ultrasonic reception module is similar to the generation module, and the key point of the receiver is also piezoelectric ceramics. The difference between ultrasonic generation 
and ultrasonic reception is the mechanism opposed. As mentioned in front, the ultrasonic generation mechanism is depends on inverse piezoelectric effect, while ultrasonic reception is depends on piezoelectric effect, which means when ultrasonic signal imposed on piezoelectric ceramics, it will be converted into electrical signal.

e) Signal processing

The electrical signal generated by ultrasonic reception is weakly and irregularly. The function of signal processing module is converts the weakly and irregularly electrical signal into standard voltage signal which can be collected by single chip microcomputer.

\section{(2) Air supply module}

The start time and terminal time of air supply for the air spring is decided by air supply module, according to controlling the state of electromagnetic valve on the air supply pipeline.

When the obtained height value between upper measuring point and lower measuring point less than lower limit value of normal range, electromagnetic valve switch on with the control of single chip microcomputer, then, the supplied air is charged into the corresponding air bag. When the height value rises to the upper limit value of normal range, electromagnetic valve switch off and cut off the air supply. So, the air pressure keeps in normal range every moment automatically.

\section{(3) Output display module}

The output display module is used to display the height value of measuring points and the service condition of air supply module.

\section{(4) Temperature compensation module}

Generally, the acoustic velocity $C$ is considered as constant, so we can get the height value $s$ by equation (1) directly. While the fact is that, acoustic velocity $C$ is influenced greatly by ambient temperature. The relationship between acoustic velocity $C$ and ambient temperature $T$ is shown in equation (2)[8,9].

$C=331.4+0.61 T$

The temperature difference in engine room is more than $50^{\circ} \mathrm{C}$, which will bring measurement error over 9.2\%. To improve measurement accuracy, temperature compensation measures is introduced into the height detecting system. So the height value $s$ is expressed as equation (3).

$s=(331.4+0.61 T) \Delta t$

\section{Processing Flow Chart}

The major function of the proposed height detecting system is monitoring the height value of given measuring points in the way of circular scanning, and make sure that value in normal range. When a certain measuring point height value is detected down to lower limit value of normal range, the electromagnetic valve on air pipelines switch on, and the supplied air is charged into the corresponding air bag. When the height value rises to the upper limit value of normal range, electromagnetic valve switch off and cut off the air supply. The processing flow chart is shown in Fig. 4. 


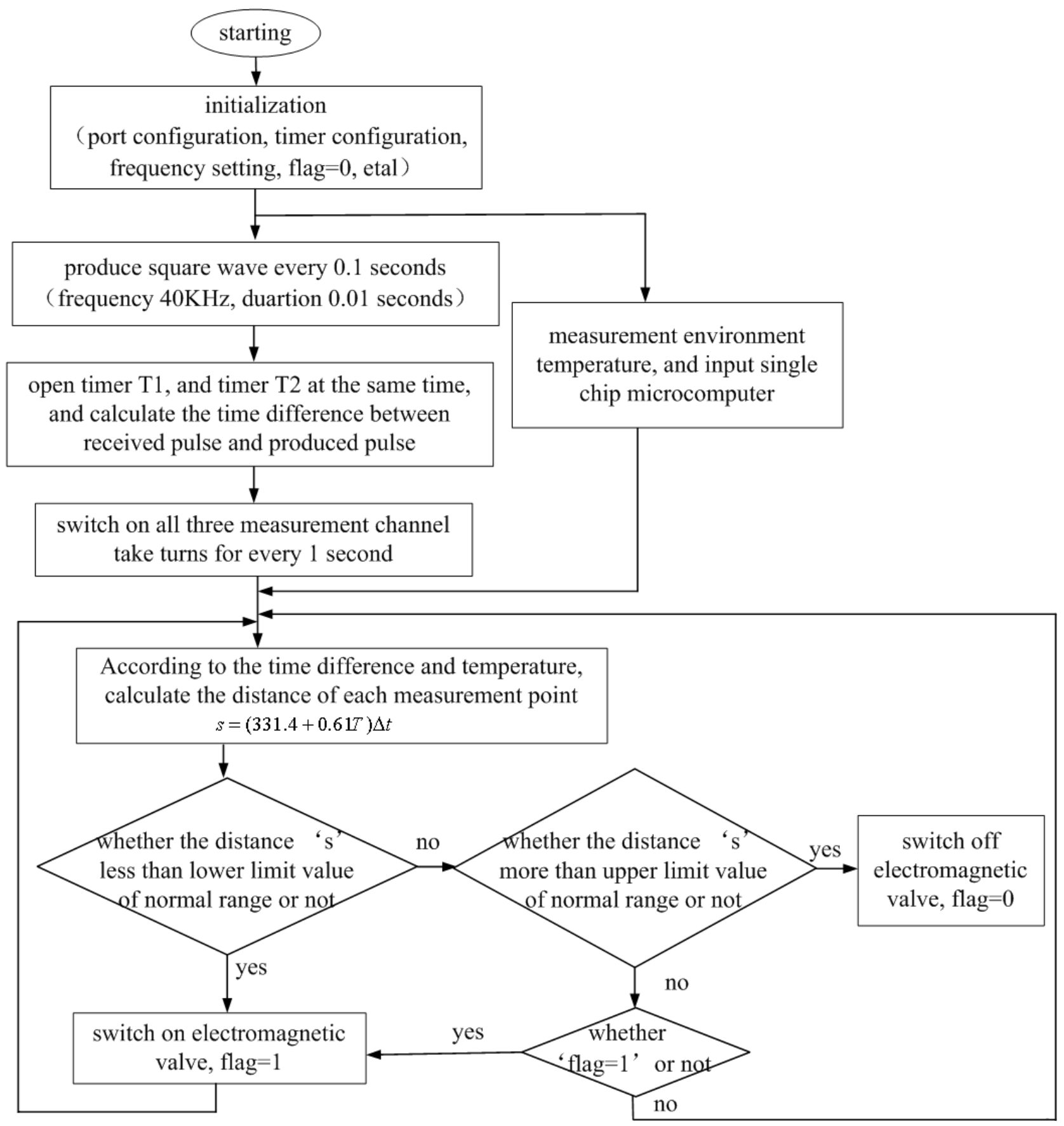

Fig.4. Processing flow chart of the height detecting system

\section{Conclusion}

In order to measure the air pressure of marine diesel engine air spring and keep it in normal range, an automatic non-contact height detecting system is presented based on ultrasonic measurement principle. The operational principle, system composition, and workflow chart is described in detail. It is concluded that, the air pressure parameters of the air spring can be remained in normal range by using the proposed detecting system.

\section{References}

[1] Lin He, Wei Xu, Naval vessel machinery mounting technology and its recent advances, Acta Acustica, 2013,38(2): 128-136.

[2] Jian-qiang Sun, Jiang-shui Han, Design optimization of ship main-engine vibration isolation system[J],Science \& Technology Information, 2008(10): 18-36. 
[3] Y. Nagayama, M. Emoto, H. Nakanishi, and S. Sudo, Control, data acquisition, data analysis and remote participation in LHD, Fusion Engineering and Design, vol. 2008, pp. 170-175, April 2008.

[4] J. Sousa, A. J. N. Batista, R. C. Pereira, and C. Varandas, “A unified real-time control and data acquisition hardware platform,” Fusion Engineering and Design, vol. 2006, pp. 1853-1858, July 2006.

[5] Hui-ying Liu, Bao-shan Fan, Study of control system of multiple step motors based on STM32, Measurement \& Control Technology, June 2010, vol. 29, pp. 54-57.

[6] He Guo, Pan Xinglong, Liang Shuhai, Gao Shilun. Research on the Designation of Diesel Engine Data Acquisition System Based on Single Chip Microcomputer STM32 [C]. 2011 International Conference on Electrical and Control Engineering. Yichang, China, 2011(2): 1228-1231.

[7] Tuan-shan Zhang, Na Zhang, Yu-ting Wu, Study of driving bipolar stepper motors based on enhanced STM32, Electronic Measurement Technology, October 2010, vol. 33, pp. 16-18.

[8] Jie Yuan, Tai-hua Chang, Design of ultrasonic distance measurement system based on STM32 microprocessor, Electronic Design Engineering, 2011, 19(15): 76-82.

[9] Xu, Yang, Xiao-fang Liu, Ze-qi Zhang, et al, Design of Ultrasonic wave distance measuring system based on microprocessor, Machine Tool \& Hydraulics, 2011, 39(8): 106-124. 